CLINICAL STUDY

\title{
Immunohistochemical identification of the PTHR1 parathyroid hormone receptor in normal and neoplastic human tissues
}

\author{
Amelie Lupp ${ }^{1}$, Christoph Klenk ${ }^{2}$, Christoph Röcken ${ }^{3}$, Matthias Evert ${ }^{4}$, Christian Mawrin ${ }^{5}$ and Stefan Schulz ${ }^{1,2}$ \\ ${ }^{1}$ Department of Pharmacology and Toxicology, Friedrich-Schiller-University, 07747 Jena, Germany, ${ }^{2}$ Department of Pharmacology and Toxicology, \\ Julius-Maximilians-University, 97078 Würzburg, Germany, ${ }^{3}$ Department of Pathology, Charité Universitätsmedizin, 10117 Berlin, Germany, \\ ${ }^{4}$ Department of Pathology, Ernst-Moritz-Arndt-University, 17487 Greifswald, Germany and ${ }^{5}$ Department of Neuropathology, Otto-von-Guericke- \\ University, 39120 Magdeburg, Germany
}

(Correspondence should be addressed to S Schulz who is now at Institut für Pharmakologie und Toxikologie, Drackendorfer Strasse 1, 07747 Jena, Germany; Email: stefan.schulz@mti.uni-jena.de)

\begin{abstract}
Background: Parathyroid hormone (PTH) is a crucial regulator of calcium homoeostasis in humans. Although it is well known that PTH acts primarily on kidney and bone, the precise cellular and subcellular sites of PTH action have not been visualised in human tissues.

Method: We developed and characterised a novel anti-peptide antibody to the carboxy-terminal region of the human PTH receptor type 1 (PTHR1). Specificity of the antiserum was demonstrated by i) detection of a broad band migrating at $M_{\mathrm{r}} 85000-95000$ in western blots of membranes from human kidney and PTHR1-transfected cells; ii) cell surface staining of PTHR1-transfected cells; iii) translocation of PTHR1 receptor immunostaining after agonist exposure; and iv) abolition of tissue immunostaining by preadsorption of the antibody with its immunising peptide. The distribution of PTHR1 receptors was investigated in 320 human tumours and their tissues of origin.

Results: In the kidney, PTHR1 receptors were predominantly detected at the basolateral plasma membrane of epithelial cells in the proximal and distal tubules but not in the thin limbs of Henle, collecting ducts or glomeruli. In bone, PTHR 1 receptors were detected as discrete plasma membrane staining of osteocytes and osteoblasts, whereas osteoclasts remained unstained. In addition, PTHR1 was found in the gut and in a number of neoplastic tissues including colorectal carcinoma, prostate cancer, renal cell carcinoma and osteosarcoma.

Conclusion: This is the first localisation of PTHR1 receptors in human tissues at the cellular level. The overexpression of PTHR1 receptors may provide a molecular basis for efficient targeting of human tumours with radiolabelled PTH analogues.
\end{abstract}

European Journal of Endocrinology 162 979-986

\section{Introduction}

Parathyroid hormone (PTH) is an 84-amino acid peptide that is involved in the control of calcium homoeostasis in mammals (1). PTH is almost exclusively synthesised in the parathyroid gland, but to some extent also in the thymus and hypothalamus. Synthesis and secretion of PTH are reciprocally regulated by the extracellular calcium concentration, which is monitored by the calcium-sensing receptor in the parathyroid gland. PTH acts primarily on the kidney and bone, mediating its effects by binding to PTH receptor type 1 (PTHR1). In the kidney, PTH stimulates the reabsorption of calcium in the distal convoluted tubule. It also leads to an enhancement of $1 \alpha$-hydroxylase activity in the kidney, thus causing an increase in calcium absorption from the intestine via an elevation of 1,25-dihydroxycholecalciferol. In bone, PTH induces calcium release by acting indirectly on osteoclasts. The direct stimulatory effect on osteoblasts leads to an increase in bone mass. In addition to calcium homoeostasis, PTH also regulates blood phosphate concentration by the inhibition of the tubular phosphate reabsorption in the kidney $(1,2)$.

PTH-related peptide (PTHrP) was originally discovered as a tumour product causing hypercalcaemia. In addition, there is compelling evidence from both in vitro and in vivo observations that PTHrP promotes tumour cell growth, aggressiveness and metastasis (3-13). However, PTHrP is not only produced in tumours but also in a wide variety of non-malignant tissues, where it can act in an endocrine, paracrine or autocrine manner. In the foetus, PTHrP is present in many tissues such as skin, mammary glands, lung, gut, bone and teeth, and is thought to regulate cell proliferation and differentiation during organogenesis $(4,14-18)$. PTHrP exhibits N-terminal homology with PTH. PTH and 
PTHrP bind with equal affinity and efficacy to PTHR1 (19), and their effects on calcium and phosphate homoeostasis are largely indistinguishable. In fact, the amino-terminal 34 amino acids of both PTH and PTHrP are sufficient for the activation of the PTHR 1 receptor.

In addition to PTHR1, a second G protein-coupled PTH receptor, PTHR2, has been identified (20). The PTHR2 receptor responds to PTH, but does not interact with PTHrP. PTHR2 is expressed only in a few tissues, e.g. brain, pancreas, kidney and testis, and its physiological function is still unknown (1). In contrast, PTHR1 has been found in the classical target tissues of PTH action including kidney and bone. In parallel to the occurrence of PTHrP, PTHR1 also seems to be present in other non-malignant and malignant tissues and is thought to mediate PTHrP-dependent effects on cell proliferation and differentiation. Most previous studies have detected the PTHR 1 receptor on the mRNA level or via ligand-binding assays $(7-9,21-24)$. Consequently, only limited information is currently available concerning the cellular and subcellular localisation of the PTHR1 receptor in human tissues. These reports comprise investigations on giant cell tumours (25), chondrosarcoma (8), ameloblastoma (26), medulloblastoma (27), prostate cancer (13), breast cancer $(28,29)$ and gastric cancer $(30)$. To the best of our knowledge there are currently no more extensive studies involving other human tumour species and investigating different types of tumours in parallel.

Thus, the aim of the present study was to evaluate the prevalence and cellular localisation of PTHR 1 in a total of 320 samples from 18 different human tumour entities by means of immunohistochemistry. For this purpose, we have generated and characterised a novel antibody directed to the carboxy-terminal sequence of the PTHR1 receptor. We have also developed an immunohistochemical protocol that allows an efficient detection of this receptor in formalin-fixed, paraffinembedded human tissues.

\section{Materials and methods}

\section{Tissue specimens}

A total of 320 tumour specimens were obtained from the Departments of Pathology of the Otto-von-Guericke University, Magdeburg and the Charité, Berlin, Germany. All tissue specimens had been fixed in formalin and embedded in paraffin. The following tumour species were investigated: renal cell carcinoma $(n=44$, classified as clear cell carcinoma $(n=25)$, papillary type $(n=12)$ or chromophobic type $(n=7))$, osteosarcoma $(n=4)$, gastric adenocarcinoma $(n=12)$, colorectal adenocarcinoma $(n=11)$, ductal pancreatic adenocarcinoma $(n=18)$, breast carcinoma $(n=41)$, ovarian carcinoma $(n=44)$, adenocarcinoma of the corpus uteri $(n=4)$, squamous cell carcinoma of the cervix uteri $(n=13)$, endometriosis $(n=6)$, prostate adenocarcinoma $(n=16)$, carcinoid $(n=15)$, pancreatic insulinoma $(n=4)$, pituitary adenoma $(n=20)$, pheochromocytoma $(n=22)$, glioblastoma $(n=23)$, astrocytoma $(n=15)$ and melanoma $(n=8)$. Several of the tumour specimens contained adjacent normal tissue, which was also analysed. In addition, fresh samples from kidney tissue and from different parts of the gut were obtained from the Department of Urology, Friedrich-Schiller-University, Jena, Germany and from the Department of Pathology, Ernst-Moritz-ArndtUniversity, Greifswald, Germany respectively. Samples were immediately frozen in liquid nitrogen and were stored at $-80^{\circ} \mathrm{C}$ until western blot analysis.

\section{Generation and purification of the PTHR 1 antibody}

Polyclonal antisera were generated against the carboxyterminal tail of the human PTHR1 receptor. The identity of the peptide used for the immunisation of the rabbits was EEASGPERPPALLQEEWETVM. The peptide was custom synthesised by Gramsch Laboratories (Schwabhausen, Germany), purified by HPLC and coupled to keyhole limpet haemocyanin as described previously $(31,32)$. The conjugate was mixed 1:1 with Freund's adjuvant and injected into three rabbits (1781-1783) for PTHR1 antisera production. Animals were injected at 4 -week intervals, and serum was obtained 2 weeks after immunisations beginning with the second injection. The specificity of the antisera was initially tested using immuno-dot blot analysis as described $(31,32)$. For subsequent analysis, antibodies were affinity purified against their immunising peptide using the Pierce SulfoLink Immobilization Kit for Peptides (Thermo Scientific, Rockford, IL, USA) according to the instructions of the manufacturer. In initial dot blot analyses and preliminary immunohistochemical investigations, the antiserum (1781) displayed high affinity along with strong and specific immunostaining. This antiserum was therefore used throughout the study.

\section{Immunocytochemistry}

Chinese hamster ovary (CHO) cells were stably transfected with a plasmid encoding for the human hemagglutinin (HA)-tagged PTHR1 receptor (HA-PTHR1) (33). Cells were grown on coverslips overnight either with or without subsequent 30-min exposure to human PTH (1-34) (Bachem, Weil am Rhein, Germany). Cells were then fixed and incubated with $1 \mu \mathrm{g} / \mathrm{ml}$ anti-PTHR1 (1781) antibody or $1 \mu \mathrm{g} / \mathrm{ml}$ anti-HA (HA.11) antibody (Covance, Princeton, NJ, USA) followed by Cy2-conjugated secondary antibodies (Dianova, Hamburg, Germany). Specimens were mounted as described previously and examined using a Leica TCS SP5 laser scanning confocal microscope (Leica, Wetzlar, Germany) (31). 


\section{Western blot analysis}

Lysates were prepared from stably transfected CHO cells as well as from fresh human kidney or gut tissue as described (31). Samples were then subjected to $8 \%$ SDS-PAGE and immunoblotted onto nitrocellulose. Blots were incubated with $0.1 \mu \mathrm{g} / \mathrm{ml}$ anti-PTHR1 (1781) antibody or $1 \mu \mathrm{g} / \mathrm{ml}$ anti-HA (HA.11) antibody followed by a peroxidase-conjugated secondary antibody incubation and ECL detection (Amersham). For adsorption controls, the antiserum was preincubated with $10 \mu \mathrm{g} / \mathrm{ml}$ of the peptide used for immunisation of the rabbits for $2 \mathrm{~h}$ at room temperature.

\section{Immunohistochemistry}

Five-micrometer sections were prepared from the paraffin blocks and floated onto positively charged slides. Immunostaining was performed by an indirect peroxidase labelling method as described previously (34). Briefly, sections were dewaxed, microwaved in $10 \mathrm{mM}$ citric acid $(\mathrm{pH} 6.0)$ for $16 \mathrm{~min}$ at $600 \mathrm{~W}$ and then incubated with $0.1 \mu \mathrm{g} / \mathrm{ml}$ anti-PTHR1 (1781) antibody overnight at $4{ }^{\circ} \mathrm{C}$. Detection of the primary antibody was performed using a biotinylated anti-rabbit IgG followed by an incubation with peroxidaseconjugated streptavidin (BioGenex, San Ramon, CA, USA). Sections were developed by incubation in 3-amino-9-ethylcarbazole (AEC) in acetate buffer (BioGenex). The sections were then rinsed, counterstained with Mayer's haematoxylin and mounted in glycerol. For immunohistochemical controls, the primary antibody was either omitted, replaced by preimmune serum or adsorbed for $2 \mathrm{~h}$ at room temperature with $10 \mu \mathrm{g} / \mathrm{ml}$ of the peptide used for immunisations. To assign the immunostaining to the different tubular segments of the kidneys, additional double-labelling experiments were performed. For this purpose, kidney sections were incubated overnight at $4{ }^{\circ} \mathrm{C}$ with $0.1 \mu \mathrm{g} / \mathrm{ml}$ anti-PTHR 1 (1781) antibody together with one of the following antibodies: polyclonal goat anti-human thiazide-sensitive sodium/chloride cotransporter (NCC; Santa Cruz Biotechnology, Santa Cruz, CA, USA; dilution: 1:500) as a marker for initial distal convoluted tubules (35); monoclonal mouse antihuman sodium/calcium exchanger 1 (NCX1; Acris Antibodies $\mathrm{GmbH}$, Hiddenhausen, Germany; dilution: 1:1000) for distal convoluted tubules and connecting ducts (35); monoclonal mouse anti-human TammHorsfall protein (THP; Biozol, Eching, Germany, dilution: 1:1000) for thick ascending limbs of loops of Henle (distal straight tubules) (36); monoclonal mouse anti-human aquaporin 1 (AQP1; clone 1/A5F6; AbD Serotec, Morphosys UK Ltd, Oxford, UK; dilution: 1:500) for proximal tubules and the thin descending limbs of loops of Henle (37). Detection of the anti-PTHR1 (1781) antibody was performed using an Alexa Fluor 488-coupled anti-rabbit IgG (Invitrogen), and the other antibodies were visualised using Cy3-conjugated secondary anti-goat or anti-mouse antibodies (Dianova) respectively. Specimens were mounted and examined using a Leica TCS SP5 laser scanning confocal microscope.

\section{Evaluation of the staining patterns}

Two independent investigators evaluated all immunohistochemical stainings. The presence or absence of staining and the intensity of the colour were noted as well as the number of cells showing a positive staining and whether or not the immunoreactivity was localised to the plasma membrane. Tumours were only categorised as positive if the majority of tumour cells displayed a moderate to strong staining of the plasma membrane and/or the cytoplasm.

\section{Results}

\section{Characterisation of the PTHR1 antibody}

The specificity of the PTHR1 (1781) antiserum was monitored using western blot analysis. When membrane preparations from CHO cells stably transfected with HA-PTHR1 were electrophoretically separated and blotted onto nitrocellulose, the anti-HA antibody as well as the anti-PTHR1 (1781) antiserum revealed a broad band migrating at $M_{r} 85$ 000-95 000. In contrast, no respective band was detected with either antiserum in membrane preparations from non-transfected wild-type CHO cells (Fig. 1A). The antiserum was also tested for possible cross-reactivity with other proteins present in human tissues. When membrane preparations from normal kidney tissue were electrophoretically separated and blotted onto nitrocellulose, the anti-PTHR1 (1781) antiserum detected a broad band migrating at $M_{\mathrm{r}}$ 85 000-95000 (Fig. 1B). This immunoreactive band was completely abolished by preadsorption of the antiserum with $10 \mu \mathrm{g} / \mathrm{ml}$ of the immunising peptide (Fig. 1B). The evaluation of a series of tissue specimens of the gut revealed a similar immunoreactive band in the colon but not in the duodenum or ileum (data not shown). In addition to western blot analysis, the antiserum was characterised by immunocytochemical staining of transfected cells. When $\mathrm{CHO}$ cells stably expressing HA-PTHR1 were stained either with anti-HA (HA.11) or anti-PTHR1 (1781) antiserum, a distinct immunofluorescence localised at the level of the plasma membrane was detected (Fig. 1C). After incubation with human PTH (1-34), the HA immunoreactivity as well as the PTHR 1 immunoreactivity was translocated from the plasma membrane into the cytosol, indicating that the receptors underwent rapid agonist-dependent endocytosis (Fig. 1C). 

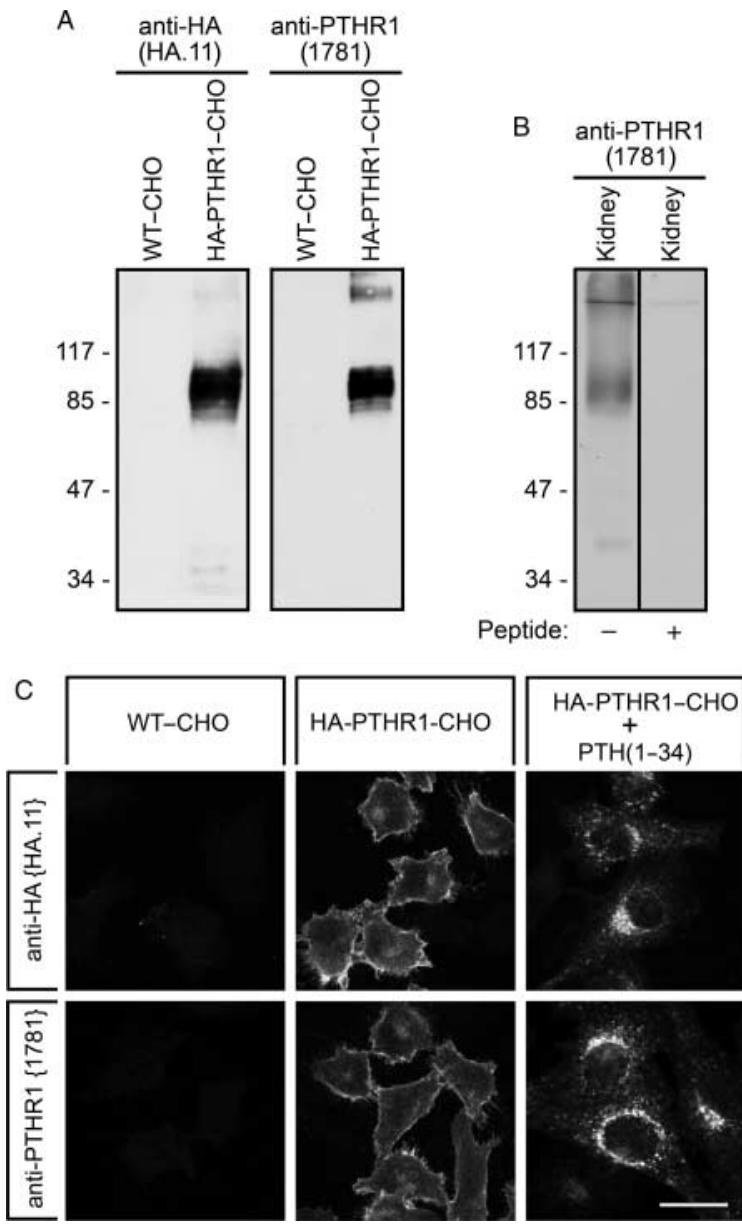

Figure 1 Analysis of the specificity of the PTHR1 (1781) antiserum. (A and $B$ ) Western blot analysis in membrane preparations $(A)$ from non-transfected wild-type $\mathrm{CHO}$ cells (WT-CHO) or $\mathrm{CHO}$ cells stably transfected with HA-PTHR1 (HA-PTHR1-CHO) and (B) from normal human kidney tissue. Samples were separated on $8 \%$ SDSpolyacrylamide gels and blotted onto nitrocellulose membranes. The nitrocellulose membranes were then either incubated with affinity purified anti-HA (HA.11) (A) or with anti-PTHR1 (1781; A and B) antiserum at a concentration of $1 \mu \mathrm{g} / \mathrm{ml}$. With human kidney samples (B), incubations were additionally performed in the absence $(-)$ or presence $(+)$ of the peptide antigen. Blots were developed by means of ECL. Ordinate: migration of protein molecular weight markers $\left(M_{\mathrm{r}} \times 10^{-3}\right)$. (C) Immunocytochemistry of WT-CHO and HA-PTHR1$\mathrm{CHO}$ cells. Cells were either exposed for $30 \mathrm{~min}$ or left unexposed to human PTH (1-34), and subsequently fixed and immunofluorescently stained either with anti-HA (HA.11) or anti-PTHR1 (1781) antiserum. No staining was seen in WT-CHO cells. In untreated HA-PTHR1 cells with either antiserum, a distinct immunofluorescence was localised at the level of the plasma membrane. Agonist exposure induced a rapid translocation of the receptors from the plasma membrane into the cytosol. Scale bar, $20 \mu \mathrm{m}$.

\section{Immunohistochemical localisation of PTHR1 in human tumours and in their tissues of origin}

The anti-PTHR1 antibody was employed for immunohistochemical staining of a variety of human tumours. Many of the tumour specimens contained adjacent non-malignant tissue, which enabled us to analyse the distribution of PTHR1 in normal tissues as well. A set of positively stained tissues was also incubated with antibodies preadsorbed with the immunising peptide, which in each case led to a complete abolition of immunostaining (Fig. 2B, insert in Fig. 2I).

A distinct immunoreactivity for PTHR1 was observed in normal kidney tissue (Fig. 2A, D, E and F). PTHR1 was present in the epithelial cells of the proximal and distal tubules, whereas the thin limbs of Henle and the collecting ducts were negative. Immunostaining was also not seen in the glomeruli with the only exception of the Goormaghtigh's cells of the juxtaglomerular apparatus. In all tubular cells, the immunoreactivity was predominantly localised at the basolateral plasma membrane. The staining of the cytoplasm was much less intense. To exactly allocate the immunostaining for PTHR1 to the different tubular segments, additional double-labelling experiments were performed (Fig. 3). There was a complete colocalisation of PTHR 1 and NCC in the initial distal convoluted tubules (Fig. 3A-C) and of PTHR1 and NCX1 in the late distal convoluted tubules and connecting ducts (Fig. 3D-F). In all cases, the glomeruli were completely devoid of staining. Both PTHR1 and THP were present in the thick ascending limbs of Henle, whereas the proximal tubules were stained positively for PTHR1 only. Neither PTHR1 nor THP was observed in collecting ducts (Fig. 3G-I). As expected, AQP1 was found in proximal tubules as well as in thin descending limbs of loops of Henle. A staining for PTHR1, however, was seen in proximal tubules only (Fig. 3J-L).

In bone, a discrete immunostaining of the plasma membrane of osteocytes as well as of osteoblasts was observed (Fig. 2G). In the duodenum, jejunum, ileum and colon ascendens, a distinct staining of isolated small groups of epithelial cells was noticed. These cells were exclusively found at the bottom of the crypts, and the immunoreactivity was clearly localised at the basolateral membrane (Fig. 2H). In the colon transversum, colon descendens, colon sigmoideum and rectum, the staining was not restricted to the bottom of the crypts, but was present in all epithelial cells. Again, the immunostaining was confined to the basolateral membrane of the cells (Fig. 2I). The acinar cells of the prostate gland were strongly positive for PTHR1 as well. Also in this case, the immunoreactivity was predominantly localised at the plasma membrane, but a slight to moderate staining was also seen in the cytoplasm. A slight to moderate staining of the cytosol was further noticed in cells of the sebaceous gland and cells of the epithelial hair sheath of normal skin as well as cell clusters within all three parts of the adrenal cortex. No immunostaining for PTHR1 was seen in the tumour-free tissue from stomach, mammary, ovary, cervix and corpus uteri or pituitary gland (not shown). 

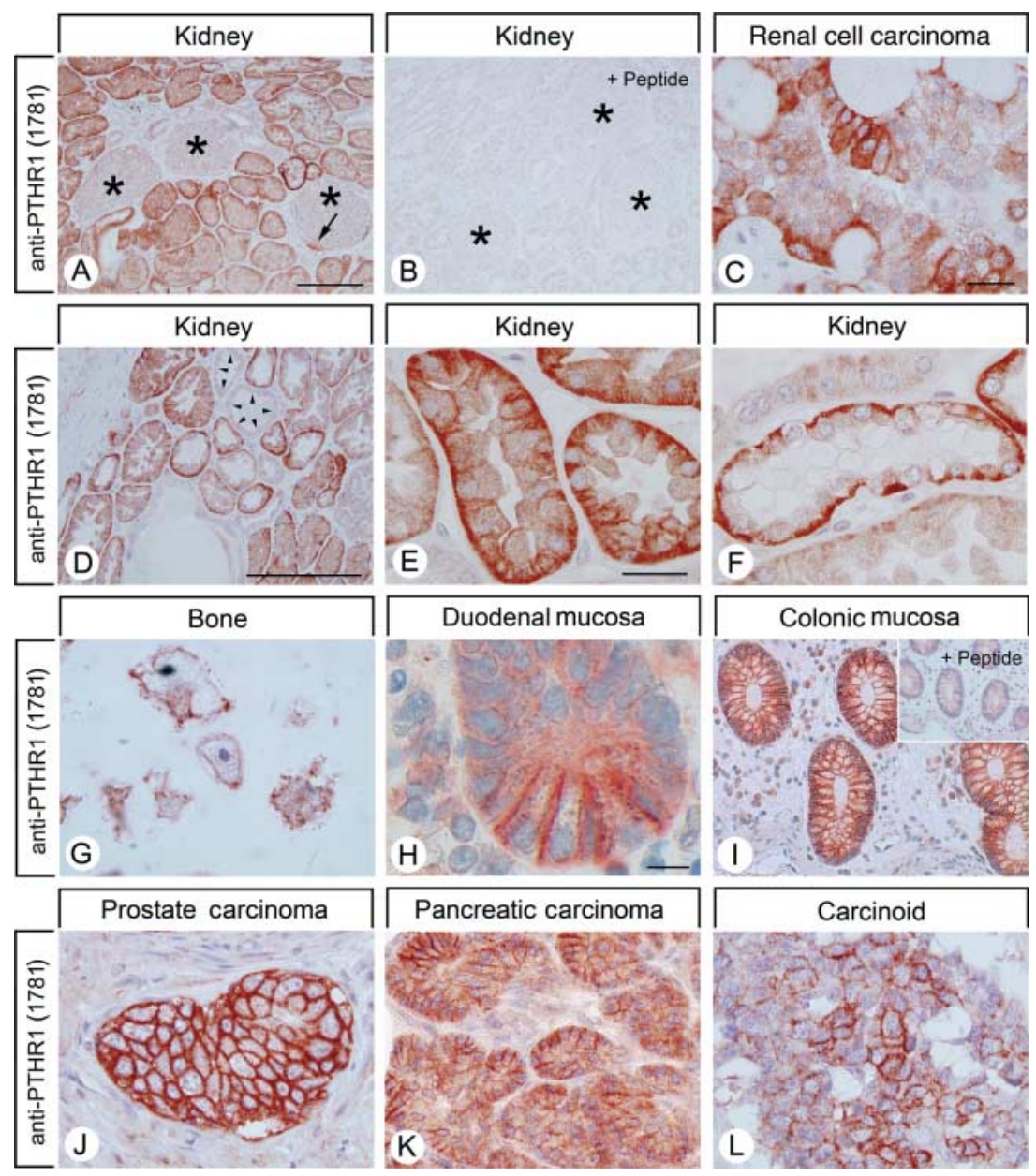

Figure 2 Immunohistochemical localisation of PTHR1 in human kidney, bone and intestinal mucosa (A, B and D- I) and in renal cell carcinoma, prostate adenocarcinoma, pancreatic adenocarcinoma and carcinoid ( $C$ and $J-L)$. Sections were dewaxed, microwaved in citric acid and incubated with the affinity purified antiPTHR1 (1781) antibody at a concentration of $0.1 \mu \mathrm{g} / \mathrm{ml}$. Sections were then sequentially treated with biotinylated anti-rabbit IgG and peroxidase-conjugated streptavidin. Finally, the colour was developed by incubation in AEC, and sections were counterstained with haematoxylin.

$\mathrm{B}$, insert in I, for adsorption controls, the primary antibody was incubated with $10 \mu \mathrm{g} / \mathrm{ml}$ of the peptide used for immunisations. Note that the immunostaining was predominantly localised at the plasma membrane. Asterisks in A and B, glomeruli; arrow in A, Goormaghtigh's cells of the juxtaglomerular apparatus; arrowheads in $\mathrm{D}$, collecting ducts. Scale bars, $A, B=200 \mu \mathrm{m}$; $\mathrm{D}=100 \mu \mathrm{m} ; \mathrm{E}, \mathrm{F}, \mathrm{I}=50 \mu \mathrm{m}$;

C, G, J, K, L $=25 \mu \mathrm{m} ; \mathrm{H}=10 \mu \mathrm{m}$.
The prevalence of PTHR1 in tumours is summarised in Table 1. Expression of PTHR 1 was observed in all cases of colorectal carcinoma, prostate adenocarcinoma and melanoma. Immunostaining for PTHR 1 was frequently found in renal cell carcinoma $(23 \%)$, especially the papillary type (42\%), in ductal pancreatic adenocarcinoma $(44 \%)$ and in osteosarcoma $(50 \%)$. PTHR1 was also observed in some samples of corpus uteri carcinoma $(25 \%)$, breast carcinoma $(17 \%)$, ovarian carcinoma (14\%), cervix uteri carcinoma (15\%), pituitary adenoma (15\%) and pheochromocytoma $(9 \%)$. While the staining pattern was homogeneous in renal cell carcinoma and prostate adenocarcinoma, most other tumour samples exhibited a heterogeneous distribution of PTHR 1 immunostaining. In renal cell carcinomas, colorectal carcinomas, pancreatic adenocarcinomas, prostate adenocarcinomas and carcinoids, the receptor was predominantly localised at the plasma membrane (Fig. 2C and J-L). In most other tumours, the PTHR 1 immunoreactivity was mainly distributed throughout the cytosol (not shown).

\section{Discussion}

In an effort to visualise the cellular and subcellular sites of action of PTH and PTHrP in human tissues, we generated an antibody that exerts a selective specificity for human PTHR1 receptor. We showed that the carboxy-terminal tail of PTHR 1 can serve as an epitope for the generation of an antiserum that effectively stains formalin-fixed, paraffin-embedded human tissues. There is evidence that the anti-PTHR1 (1781) antibody specifically detects its targeted receptor and does not crossreact. First, in western blot analyses of crude extracts from PTHR1-transfected cells, human kidney and distal human gut, the anti-PTHR 1 antibody detected a broad band migrating at $M_{\mathrm{r}} 85000-$ 95000 , which corresponds to the expected size of the glycosylated form of the receptor. Secondly, the immunoreactive band detected in membrane preparations from normal human kidney tissue and from samples of the distal normal human gut was completely abolished by preadsorption of the antibody with its 

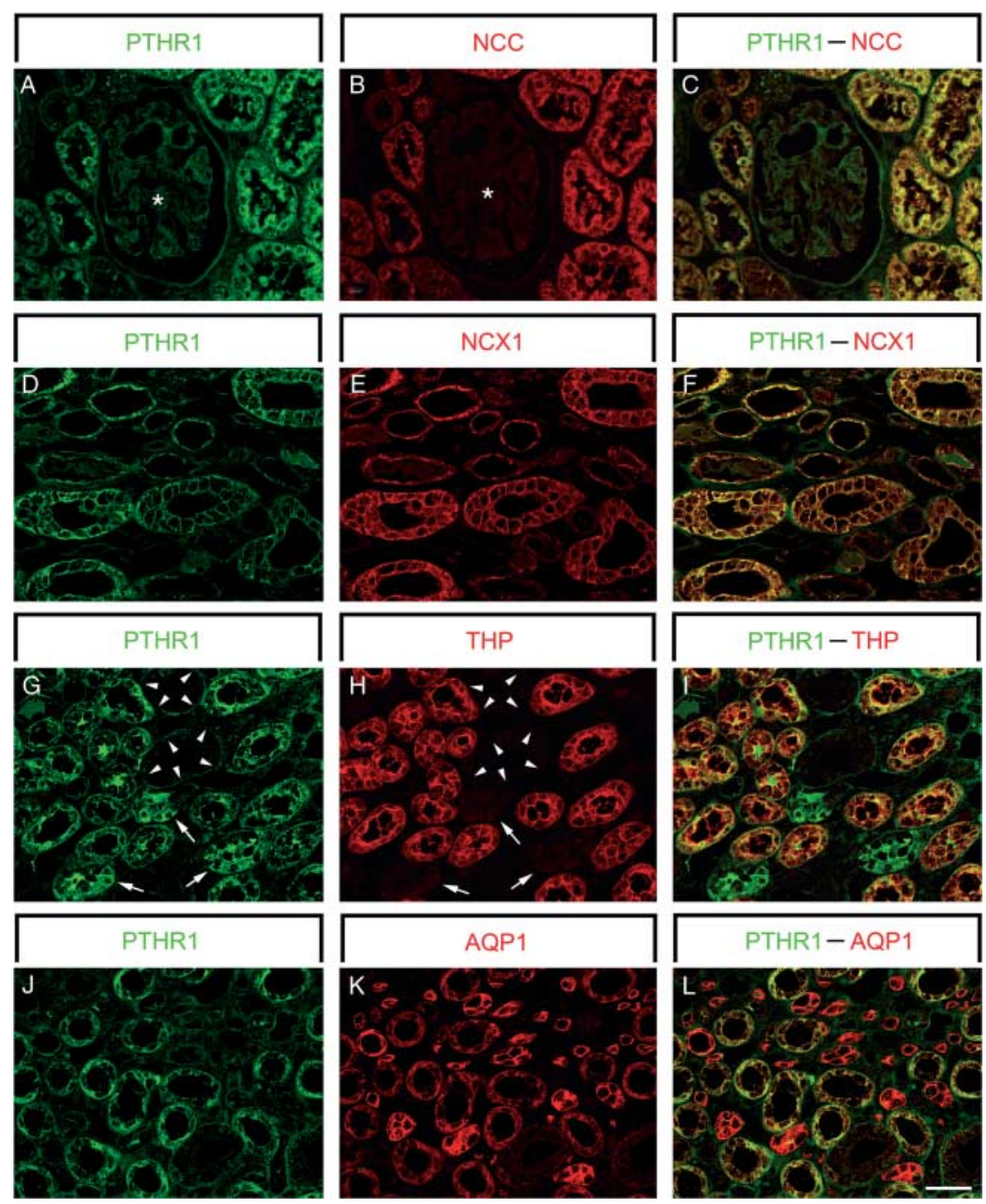

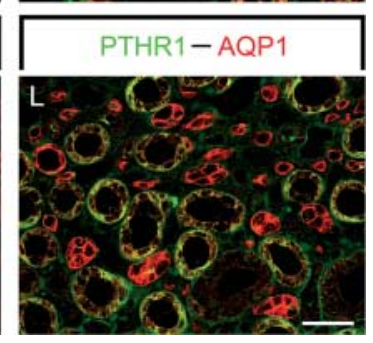

Figure 3 Double labelling of human kidney samples for PTHR1 (in green; A, D, G and $\mathrm{J})$ and for thiazide-sensitive sodium/ chloride cotransporter (NCC; in red), as a marker for initial distal convoluted tubules (B; merge: C), for sodium/calcium exchanger 1 (NCX1), indicating late distal convoluted tubules and connecting ducts (E; merge: F), for Tamm-Horsfall protein (THP), marking thick ascending limbs of loops of Henle $(\mathrm{H}$; merge: I), or aquaporin 1 (AQP1), as an indicator of proximal tubules and thin descending limbs of loops of Henle (K; merge: L). Sections were dewaxed, microwaved in citric acid and incubated with the affinity purified anti-PTHR1 (1781) antibody at a concentration of $0.1 \mu \mathrm{g} / \mathrm{ml}$ together with one of the four marker antibodies at a dilution of $1: 500$ or $1: 1000$ respectively. Detection of the anti-PTHR1 (1781) antibody was performed using an Alexa Fluor 488-coupled anti-rabbit IgG, and the marker antibodies were visualised using Cy3-conjugated secondary anti-goat or anti-mouse antibodies respectively.

There was a complete colocalisation of PTHR1 and NCC or NCX1 in the initial and late distal convoluted tubules and connecting ducts $(\mathrm{A}-\mathrm{F})$. Both PTHR1 and THP were present in the thick ascending limbs of Henle, whereas proximal tubules were stained positively for PTHR1 only (G-I). AQP1 was found in proximal tubules as well as in thin descending limbs of loops of Henle, but PTHR1 was seen in proximal tubules only $(\mathrm{J}-\mathrm{L})$. Asterisks in $\mathrm{A}$ and $\mathrm{B}$, glomeruli; arrows in $\mathrm{G}$ and $\mathrm{H}$, proximal tubules; arrowheads in $\mathrm{G}$ and $\mathrm{H}$, collecting ducts. Scale bars, $A-L=50 \mu \mathrm{m}$. immunising peptide. Thirdly, the antibody revealed a distinct staining of the cell membrane of PTHR1transfected cells. After agonist exposure, this immunostaining translocated from the cell surface to the cytosol, indicating a rapid endocytosis of the receptor. Fourthly, immunostaining of both malignant and nonmalignant tissues was completely abolished by preadsorption of the antibody with its immunising peptide. Finally, all three novel PTHR1 antisera generated in the present study gave similar results.

As expected from the classical sites of PTH action, the most prominent immunostaining was detected in normal human kidney. We observed distinct PTHR1 immunoreactivity (as confirmed also by double-labelling experiments) at the plasma membranes of the epithelial cells of proximal tubules (where PTH causes an inhibition of tubular phosphate reabsorption) and distal tubules (thick ascending limbs of loops of Henle as well as initial and late distal convoluted tubules), where PTH stimulates the reabsorption of calcium. Other parts of the nephron, which are not responsive to PTH action (thin limbs of loops of Henle and collecting ducts), were devoid of staining. In addition, a distinct immunostaining was noticed in the Goormaghtigh's cells of the juxtaglomerular apparatus. This finding may provide a plausible explanation for the observation that PTH can influence the glomerular ultrafiltration rate (38). Another classical site of action of PTH is bone. It is commonly thought that PTH exerts its anabolic effects on bone by suppressing osteoblast and osteocyte apoptosis and by increasing osteoblast proliferation (39). There is still some controversial discussion whether osteoclasts are targeted directly by PTH or indirectly via osteoblasts (40). The present investigation revealed a distinct immunostaining of the plasma membrane of osteocytes and osteoblasts in normal bone, whereas osteoclasts remained unstained. Similar observations have previously been made by means of in situ hybridisation (41). In the small intestine and in the colon ascendens, only isolated clusters of few epithelial cells in the bottom of the crypts were stained for PTHR 1. The immunostaining was confined to the basolateral 
Table 1 Prevalence of parathyroid hormone receptor type 1 (PTHR1) in human tumour samples.

\begin{tabular}{lcr}
\hline Tumour type $(n)$ & PTHR1 $(n)^{\mathrm{a}}$ & $\%$ \\
\hline Renal cell carcinoma (44) & 10 & 23 \\
Clear cell carcinoma (25) & 4 & 16 \\
Papillary type (12) & 5 & 42 \\
Chromophobic type (7) & 1 & 14 \\
Osteosarcoma (4) & 2 & 50 \\
Gastric adenocarcinoma (12) & 1 & 8 \\
Colorectal carcinoma (11) & 11 & 100 \\
Ductal pancreatic adenocarcinoma (18) & 8 & 44 \\
Breast carcinoma (41) & 7 & 17 \\
Ovarian carcinoma (44) & 6 & 14 \\
Adenocarcinoma of the corpus uteri (4) & 1 & 25 \\
Squamous cell carcinoma & 2 & 15 \\
of the cervix uteri (13) & & \\
Endometriosis (6) & 0 & 0 \\
Prostate adenocarcinoma (16) & 16 & 100 \\
Carcinoid (15) & 1 & 7 \\
Pancreatic insulinoma (4) & 0 & 0 \\
Pituitary adenoma (20) & 3 & 15 \\
Pheochromocytoma (22) & 2 & 9 \\
Glioblastoma (23) & 4 & 0 \\
Astrocytoma (15) & 0 & 100 \\
Melanoma (8) & 8 &
\end{tabular}

aTumours were only categorised as positive if the majority of tumour cells displayed a moderate to strong staining of the plasma membrane and/or the cytoplasm.

membrane of the cells. These cells may represent stem cells or Paneth cells. Interestingly, in other parts of the colon and rectum, the staining for PTHR 1 was not only confined to cells in the bottom of the crypts, but was present in all epithelial cells indicating additional sites of PTH action in the gut. A distinct immunostaining was further seen in the epithelial cells of the prostate, where it also may be involved in processes such as cell proliferation and differentiation. Additionally, our antibody revealed a staining of some cell clusters within the adrenal cortex supporting the observation that PTH administration can cause an increase in blood cortisol and aldosterone levels (42).

In parallel to the occurrence and expression of PTHrP in many malignant tissues, where it promotes tumour cell growth, aggressiveness and skeletal metastasis, the PTHR1 receptor also appears to occur in these tissues. In the present study, PTHR1 was observed in all tissue samples of colorectal carcinoma and prostate adenocarcinoma and in some cases of osteosarcoma, renal cell carcinoma, gastric cancer and breast carcinoma. Additionally, immunostaining for PTHR 1 was detected in melanoma and in some cases of ductal pancreatic adenocarcinoma, corpus and cervix uteri carcinoma, ovarian carcinoma, pituitary adenoma and pheochromocytoma. In renal cell carcinomas, colorectal carcinomas, prostate adenocarcinomas and carcinoids, the receptor was mainly localised at the plasma membrane of the tumour cells, whereas in all other tumours immunoreactivity to PTHR 1 was distributed throughout the cytosol. The biological significance of cytosolic PTHR1 expression in these tumours is as yet unknown.
In conclusion, we have generated and characterised a novel anti-PTHR1 antibody, which enabled us to visualise PTHR1 receptors in human formalin-fixed, paraffin-embedded tissues. PTHR1 was localised at the cellular level in some human tumours investigated in the present investigation and in their tissues of origin for the first time. Since the receptor was found in many tumour species, it may provide a valuable target for both diagnosis and therapy. Thus, immunohistochemical PTHR1 visualisation may be helpful to identify those tumours with sufficient receptor overexpression as a possible target for diagnostic and/or therapeutic intervention using radiolabelled PTH analogues.

\section{Declaration of interest}

The authors declare that there is no conflict of interest that could be perceived as prejudicing the impartiality of the research reported.

\section{Funding}

This research did not receive any specific grant from any funding agency in the public, commercial or not-for-profit sector.

\section{References}

1 Gensure RC, Gardella TJ \& Jüppner H. Parathyroid hormone and parathyroid hormone-related peptide, and their receptors. Biochemical and Biophysical Research Communications 2005328 666-678.

2 Bacic D, Lehir M, Biber J, Kaissling B, Murer H \& Wagner CA. The renal $\mathrm{Na}^{+}$/phosphate cotransporter NaPi-IIa is internalized via the receptor-mediated endocytic route in response to parathyroid hormone. Kidney International 200669 495-503.

3 Philbrick WM, Wysolmersli JJ, Galbraith S, Holt E, Orloff JJ, Yang KH, Vasavada RC, Weir EC, Broadus AE \& Stewart AF. Defining the roles of the parathyroid hormone-related protein in normal physiology. Physiological Reviews 199676 127-173.

4 Strewler GJ. The physiology of parathyroid hormone-related protein. New England Journal of Medicine 2000342 177-185.

5 Birch MA, Carron JA, Scott M, Fraser WD \& Gallagher JA. Parathyroid hormone (PTH)/PTH-related protein (PTHrP) receptor expression and mitogenic responses in human breast cancer cell lines. British Journal of Cancer 1995 72 90-96.

6 Guise TA, Yin JJ, Taylor SD, Kumagi Y, Dallas M, Boyce BF, Yoneda T \& Mundy GR. Evidence for a causal role of parathyroid hormone-related protein in the pathogenesis of human breast cancer-mediated osteolysis. Journal of Clinical Investigation 1996 98 1544-1549.

7 Dougherty KM, Blomme EAG, Koh AJ, Henderson JE, Pienta KJ, Rosol TJ \& McCauley LK. Parathyroid hormone-related protein as a growth regulator of prostate carcinoma. Cancer Research 199959 6015-6022.

8 Kunisada T, Moseley JM, Slavin JL, Martin TJ \& Choong PF. Co-expression of parathyroid hormone-related protein (PTHrP) and PTH/PTHrP receptor in cartilaginous tumours: a marker for malignancy? Pathology 200234 133-137.

9 Linforth R, Anderson N, Hoey R, Nolan T, Downey S, Brady G, Ashcroft L \& Bundred N. Coexpression of parathyroid hormone related protein and its receptor in early breast cancer predicts poor patient survival. Clinical Cancer Research 20028 3172-3177.

10 Tovar-Sepulveda VA \& Falzon M. Parathyroid hormone-related protein enhances PC-3 prostate cancer cell growth via both autocrine/paracrine and intracrine pathways. Regulatory Peptides $2002105109-120$. 
11 Massfelder T, Lang H, Schordan E, Lindner V, Rothhut S, Welsch S, Simon-Assmann P, Barthelmebs M, Jacqmin D \& Helwig JJ. Parathyroid hormone-related protein is an essential growth factor for human clear cell renal carcinoma and a target for the Von Hippel-Lindau tumor suppressor gene. Cancer Research 200464 $180-188$.

12 Deftos LJ, Barken I, Burton DW, Hoffman RM \& Geller J. Direct evidence that PTHrP expression promotes prostate cancer progression in bone. Biochemical and Biophysical Research Communications 2005327 468-472.

13 Perez-Martinez FC, Alonso V, Sarasa JL, Nam-Cha SG, VelaNavarrete R, Manzarbeitia F, Calahorra FJ \& Esbrit P. Immunohistochemical analysis of low-grade and high-grade prostate carcinoma: relative changes of parathyroid hormone-related protein and its parathyroid hormone 1 receptor, osteoprotegerin and receptor activator of nuclear factor-kB ligand. Journal of Clinical Pathology 200760 290-294.

14 Schipani E, Lanske B, Hunzelman J, Kovacs CS, Lee K, Pirro A, Kronenberg HM \& Jüppner $\mathrm{H}$. Targeted expression of constitutively active receptors for parathyroid hormone and parathyroid hormone-related peptide delays endochondral bone formation and rescues mice that lack parathyroid-hormone-related peptide. PNAS 199794 13689-13694.

15 Foley J, Longely BJ, Wysolmerski JJ, Dreyer BE, Broadus AE \& Philbrick WM. Regulation of epidermal differentiation by PTHrP: evidence from PTHrP-null and PTHrP-overexpressing mice. Journal of Investigative Dermatology 1998111 1122-1128.

16 Philbrick WM, Dreyer BE, Nakchbandi IA \& Karaplis AC. Parathyroid hormone-related protein is required for tooth eruption. PNAS 199895 11846-11851.

17 Wysolmerski JJ, Philbrick WM, Dunbar ME, Lanske B, Kronenberg $\mathrm{H}$ \& Broadus AE. Rescue of the parathyroid hormone-related protein knockout mouse demonstrates that parathyroid hormone-related protein is essential for mammary gland development. Development 1998125 1285-1294.

18 Kronenberg HM. Developmental regulation of the growth plate. Nature 2003423 332-336.

19 Jüppner H, Abou-Samra A, Freeman MW, Kong XF, Schipani E, Richards J, Kolakowski LF, Hock J, Potts JT, Kronenberg HM \& Segre GV. A G protein-linked receptor for parathyroid hormone and parathyroid hormone-related peptide. Science 1991254 1024-1026.

20 Usdin TB, Gruber C \& Bonner TI. Identification and functional expression of a receptor selectively recognizing parathyroid hormone, the PTH2 receptor. Journal of Biological Chemistry $199527015455-15458$.

21 Carron JA, Fraser WD \& Gallagher JA. PTHrP and the PTH/PTHrP receptor are co-expressed in human breast and colon tumours. British Journal of Cancer $1997 \mathbf{7 6}$ 1095-1098.

22 Iddon J, Bundred NJ, Hoyland J, Downey SE, Baird P, Salter D, McMahon R \& Freemont AJ. Expression of parathyroid hormonerelated protein and its receptor in bone metastases from prostate cancer. Journal of Pathology 2000191 170-174.

23 Hoey RP, Sanderson C, Iddon J, Brady G, Bundred NJ \& Anderson NG. The parathyroid hormone-related protein receptor is expressed in breast cancer bone metastases and promotes autocrine proliferation in breast carcinoma cells. British Journal of Cancer 200388 567-573.

24 Yang R, Hoang BH, Kubo T, Kawano H, Chou A, Sowers R, Huvos AG, Meyers PA, Healey JH \& Gorlick R. Over-expression of parathyroid hormone type 1 receptor confers an aggressive phenotype in osteosarcoma. International Journal of Cancer 2007 121 943-954.

25 Nakashima M, Nakayama T, Ohtsuru A, Fukada E, Niino D, Yamazumi K, Naito S, Ito M \& Sekine I. Expression of parathyroid hormone (PTH)-related peptide (PTHrP) and PTH/PTHrP receptor in osteoclast-like giant cells. Pathology, Research and Practice 2003 $19985-92$.
26 Ohtsuru M. Expression of parathyroid hormone-related protein in ameloblastomas. Tokai Journal of Experimental and Clinical Medicine $200530233-239$.

27 Gessi M, Monego G, Calviello G, Lanza P, Giangaspero F, Silvestrini A, Lauriola L \& Ranelletti FO. Human parathyroid hormone-related protein and human parathyroid hormone receptor type 1 are expressed in human medulloblastomas and regulate cell proliferation and apoptosis in medulloblastomaderived cell lines. Acta Neuropathologica 2007114 135-145.

28 Iezzoni JC, Bruns ME, Frierson HF, Scott MG, Pence MA, Deftos LJ \& Bruns DE. Coexpression of parathyroid hormone-related protein and its receptor in breast carcinoma: a potential autocrine effector system. Modern Pathology 199811 265-270.

29 Suzuki Y, Tokuda Y, Saito Y, Umemura S \& Osamura RY. Clinicopathological correlation between expression of PTHrP receptor and various prognostic factors in breast cancer without axillary lymph node metastasis. Tokai Journal of Experimental and Clinical Medicine 200530 127-132.

30 Ito M, Nakashima M, Alipov GK, Matsuzaki S, Ohtsuru A, Yano H, Yamashita S \& Sekine I. Gastric cancer associated with overexpression of parathyroid hormone-related peptide (PTHrP) and $\mathrm{PTH} / \mathrm{PTHrP}$ receptor in relation to tumor progression. Journal of Gastroenterology 199732 396-400.

31 Schulz S, Pauli SU, Handel M, Dietzmann K, Firsching U \& Höllt V. Immunohistochemical determination of five somatostatin receptors in meningioma reveals frequent overexpression of somatostatin receptor subtype sst2A. Clinical Cancer Research $200061865-1974$.

32 Schulz S, Stumm R \& Höllt V. Immunofluorescent identification of neuropeptide B-containing nerve fibers and terminals in the rat hypothalamus. Neuroscience Letters 2007411 67-71.

33 Castro M, Dicker F, Vilardaga JP, Krasel C, Bernhardt M \& Lohse MJ. Dual regulation of the parathyroid hormone (PTH)/PTH-related peptide receptor signaling by protein kinase $\mathrm{C}$ and beta-arrestins. Endocrinology 2002143 3854-3865.

34 Lupp A, Danz M \& Müller D. Morphology and cytochrome P450 isoforms expression in precision-cut rat liver slices. Toxicology $200116153-66$.

35 Lagger Biner H, Arpin-Bott MP, Loffing J, Wang X, Knepper M, Hebert SC \& Kaissling B. Human cortical distal nephron: distribution of electrolyte and water transport pathways. Journal of the American Society of Nephrology 200213 836-847.

36 Devuyst O, Dahan K \& Pirson Y. Tamm-Horsfall protein or uromodulin: new ideas about an old molecule. Nephrology, Dialysis, Transplantation 200520 1290-1294.

37 Agre P. Aquaporin water channels in kidney. Journal of the American Society of Nephrology 200011 764-777.

38 Ichikawa I, Humes HD, Dousa TP \& Brenner BM. Influence of parathyroid hormone on glomerular ultrafiltration in the rat. American Journal of Physiology 1978234 F393-F401.

39 Divieti PP. PTH and osteocytes. Journal of Musculoskeletal $\mathcal{E}$ Neuronal Interactions $2005 \mathbf{5} 328-330$.

40 Dempster DW, Hughes-Begos CE, Plavetic-Chee K, BrandaoBurch A, Cosman F, Nieves J, Neubort S, Lu SS, Iida-Klein A, Arnett T \& Lindsay R. Normal human osteoclasts from peripheral blood monocytes express PTH type 1 receptors and are stimulated by PTH in the absence of osteoblasts. Cell Biochemistry 200595 $139-148$.

41 Fermor B \& Skerry TM. PTH/PTHrP receptor expression on osteoblasts and osteocytes but not resorbing bone surfaces in growing rats. Journal of Bone and Mineral Research 199510 1935-1943.

42 Lasukova TV. Enkephalin blockade of the stimulating effect of parathormone on adrenal cortex function. Fiziologicheskii Zhurnal SSSR 199076 402-405.

Received 28 January 2010

Accepted 3 February 2010 